Статья посвящена юбилею Татьяны Гильнияхметовны Миннияхметовой - выдающегося этнолога, кандидата исторических наук, доктора философии, «Отличника народного просвещения РСФСР» (Москва, 1987 г.). Описаны этапы становления ученого; научная, популяризаторская и организаторская деятельность; показан ее вклад в исследование удмуртской традиционной культуры. За период работы Т. Г. Миннияхметова опубликовала семь авторских и коллективных монографий, а также более двухсот статей. Труды ученого востребованы не только профессиональным академическим сообществом и преподавателями высшей школы, но и всеми, кто интересуется культурой и историей удмуртского народа. На счету Т. Г. Миннияхметовой более семидесяти фольклорно-этнографических и фольклорно-диалектологических экспедиций, география которых, помимо Удмуртской Республики, охватывает соседние территории Поволжья и Приуралья, а также регионы Сибири. Ею созданы мощный банк информации по этнографии, культуре и быту удмуртов и других народов региона, а также большой архив фото-, видео- и аудиоматериалов.

Имя удмуртского этнолога известно не только в России, но и за ее пределами. Удмуртское происхождение и знание тенденций развития европейской этнологии способствуют успешной исследовательской деятельности Т. Г. Миннияхметовой как ученого, постигающего этническую культуру как «изнутри», так и в контексте развития современных этнических процессов. Научная и преподавательская деятельность юбиляра способствует широкой популяризации удмуртской этнографии и фольклора в европейской и мировой научной среде.

Ключевые слова: Т. Г. Миннияхметова, закамские удмурты, традиционная культура, этническая идентичность, фольклор, юбилей.

\title{
DOI: 10.35634/2224-9443-2021-15-1-188-192
}

Татьяна Гильнияхметовна Миннияхметова, этнолог, кандидат исторических наук, доктор философии, «Отличник народного просвещения РСФСР» (Москва, 1987 г.) родилась 3 января 1961 г. в д. Байшады Бураевского р-на Башкирии.

Этапы становления. В 1968-1976 гг. Т. Г. Миннияхметова училась в Байшадинской восьмилетней школе. После, завершив учебу уже в Тепляковской средней школе (1978 г.), год работала учителем русского языка и литературы в Байшадинской восьмилетней школе.

Окончив Удмуртский государственный университет (далее - УдГУ) в 1984 г. по специальности «фи-

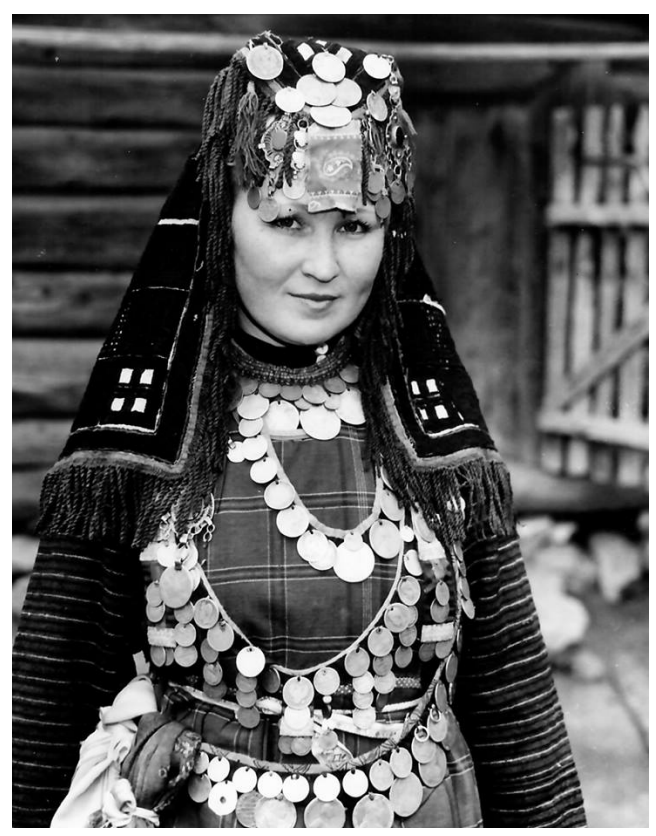


лолог, преподаватель русского языка и литературы, удмуртского языка и литературы», работала учителем и директором Байшадинской восьмилетней школы (1984-1988 гг.). А начиная с 1988 г. являлась научным сотрудником сначала Удмуртского республиканского краеведческого музея (ныне Национальный музей Удмуртской Республики им. Кузебая Герда,; далее - НМ УР), затем в 1989-1990 гг. - Удмуртского института истории, языка и литературы Уральского отделения АН СССР (ныне структурное подразделение Удмуртского федерального исследовательского центра Уральского отделения РАН, далее - УИИЯЛ УдмФИЦ УрО РАН), а в 1994-1999 гг. - Отдела народов Южного Урала в Музее археологии и этнографии Уфимского научного центра Уральского отделения Российской Академии наук (далее - УНЦ УрОРАН), ныне структурное подразделение Уфимского федерального исследовательского центра Уральского отделения РАН (далее - УФИЦ УрО РАН).

В 1990-1991 гг. прошла научную стажировку в Институте истории, языка и литературы УНЦ УрО АН СССР (ныне УНЦ УрО РАН), в 1998 г. - в Хельсинкском университете (грант СІМО, Финляндия). После завершения аспирантуры в УНЦ УрО РАН успешно защитила кандидатскую диссертацию на тему «Календарные обряды закамских удмуртов» (г. Уфа, 1996; науч. рук.- проф. Р. Г. Кузеев). Окончив очную докторантуру в Тартуском университете (Эстония; науч. рук. - проф. Уло Валк), с отличием (summa cum laude) защитила диссертацию на соискание ученой степени доктора философии на тему «Традиционные обряды закамских удмуртов: Структура. Семантика. Фольклор» (2003).

С 2003 г. занимает должность профессора-ассистента проектов «Традиционная религиозная практика удмуртов и жителей Тироля», «Энциклопедия демонологии» в Институте европейской этнологии и фольклора университета Инсбрука (Австрия) и «Ареальная типология финно-угорских, тюркских и русского языков в Волго-Уральском регионе России» в Институте языков университета Инсбрука (Австрия).

Полевые исследования. Работу в составе диалектологических и фольклорно-этнографических экспедиций Татьяна Гильнияхметовна начала еще студенткой филологического факультета УдГУ. Выезжала собирать материал к северным удмуртам в Глазовский р-н УР под руководством фольклориста Д. А. Яшина (1980 г.), к завятским удмуртам в Балтасинский р-н Татарии под научным руководством проф. В. К. Кельмакова (1981 г.). Курсовые работы писала по этнографии закамских удмуртов под руководством проф. В. Е. Владыкина, а дипломную работу подготовила и защитила под научным руководством Л. С. Христолюбовой, которая и после защиты долгие годы оставалась неизменным наставником Татьяны Гильнияхметовны.

В качестве научного сотрудника НМ УР Т. Г. Миннияхметова работала в составе этнографических экспедиций к бавлинским, косинским, сибирским, пермским, северным, южным, малмыжским, мамадышским, завятским, мари-турекско-цыпьинским, закамским удмуртам, бесермянам, крещёным татарам, староверам (организаторы - С. Х. Лебедева и А. Ю. Петерсон). В годы работы в УНЦ УрО РАН она занималась сбором полевого материала среди закамских и красноуфимских удмуртов, восточных марийцев, чувашей, северо-западных и южных башкир, русских, мордвы, латышей и эстонцев Башкирии (организатор - академик Р. Г. Кузеев). Неоднократно Т. Г. Миннияхметова выезжала в этнографические экспедиции к восточным марийцам и удмуртам совместно с финскими исследователями Ильдико Лехтинен (Ildikó Lehtinen), Сеппо Лаллукка (Seppo Lallukka), Пол Фрайер (Paul Fryer), со студентами и учеными Эстонии и Венгрии. В годы учебы в Тартуском университете свои исследования и полевые работы по Эстонии проводила под научным руководством проф. Уло Валка (Ülo Valk). В 2006 и 2008 гг. принимала участие в сборе фольклорно-этнографических материалов у венгров и закамских удмуртов совместно с венгерскими коллегами: профессорами Аттила Добо, Золтан Надь, докторантами Печского университета Богларка Мачаи и Вера Симонек. Десятки полевых исследований и научных работ выполнено ею в соавторстве с коллегой Р. Р. Садиковым. В последние годы занимается изучением этнографической группы мордвы-мурзы Башкирии совместно с коллегами из Уфы, Самары, Саранска. 
Научная деятельность. Основной сферой научных изысканий Т. Г. Миннияхметовой является календарная и семейная обрядность закамских удмуртов. В первую очередь исследователем была охарактеризована система календарной обрядности этой группы удмуртского населения, осуществлена реконструкция народного календаря и традиционных календарных обрядов. В продолжение изучения традиционной обрядовой культуры Татьяна Гильнияхметовна детально описала три аспекта обрядовой деятельности: семейно-родовые обряды, связанные с ожиданием и рождением ребенка; календарные, посвящённые празднованию Великого дня (Быдйым нунал, Великтэм, Паска); случайные или окказиональные, выполняемые при сооружении колодца. Эти три обрядовых комплекса воспринимались носителями традиционной культуры как зарождение новой эпохи в жизни каждого отдельного человека и всего социума. Впервые Т. Г. Миннияхметовой были проанализированы также фольклорные тексты, сопровождавшие отмеченные выше обрядовые действа. Далее, помимо обрядов, связанных с рождением ребенка, были изучены и другие семейные обряды: свадебные и погребально-поминальные ритуалы, обычаи, в том числе обряды ӥожи сиён (букв. 'поедание молозива') и ӟазег ишкон (букв. 'ощипывание гуся'). При этом удмуртская обрядовая сфера описана в сопоставлении с традициями соседних народов Поволжья и Приуралья.

В круг научных интересов Татьяны Гильнияхметовны входит также мифология. Ею описаны образы некоторых мифологических персонажей и представлений удмуртов: огонь, магия, символика рождения и смерти, сновидения, представления о потустороннем. Обращение ученого к исследованию этих аспектов было стимулировано работой в рамках европейского проекта «Энциклопедия демонологии», инициированного проф. Пертцольдтом в Университете г. Инсбрука (Австрия). Еще одно новое направление научной деятельности - подготовка статей по проблемам удмуртского этнофутуризма.

В последние годы Т. Г. Миннияхметова занимается сбором и систематизацией архивного материала об удмуртах, содержащегося в Фольклорном архиве Эстонского литературного музея. Её научные разработки связаны с вопросами методики полевых исследований; с проблемами этнического самосознания, отражающегося в понятиях о времени и пространстве, о реальных и символических границах; с описанием концепций «чистого и нечистого» в традиционном удмуртском обществе и мн.др.

Т. Г. Миннияхметова активно работает в международном научном сообществе «Ритуальный год» (Working Group on the Ritual Year). Эта группа организована более пятнадцати лет назад в рамках Международного общества по изучению фольклора и этнологии (Société Internationale d'Ethnologie et de Folklore, сокращённо - SIEF). Рабочая группа «Ритуальный год» занимается разработкой самых разнообразных аспектов, связанных с ритуальным годом народов мира от древности до наших дней. Ежегодно группа организует и проводит конференции и научные дискуссии, обмен информацией в рамках этой темы. Т. Г. Миннияхметова принимала участие почти во всех конференциях, инициированных этой тематической группой.

Авторитет в европейской научной среде, энергичная организаторская и научная деятельность Татьяны Гильнияхметовны нашли отражение в ее участии в проведении X научной конференции «Ritual Year - 2014» в университете г. Инсбрука (Австрия) на тему «Magic in Ritual and Ritual in Magic = Магия в ритуале и ритуал в магии». Именно Т. Г. Миннияхметовой было поручено стать одним из главных организаторов конференции и соредактором подготовленного по ее итогам научного сборника (2015 г.).

Кроме того, Татьяна Гильнияхметовна вела преподавательскую работу в Университетах г. Печ (Венгрия), г. Тарту (Эстония); выступала в Венгерской Академии наук (г. Будапешт).

Основные научные заслуги. На протяжении нескольких десятилетий юбиляр продолжает проводить полевые исследования. Ею собран оригинальный фольклорно-этнографический материал по разным локальным группам удмуртского населения, по другим финно-угорским, славянским и тюркоязычным народам Поволжско-Приуральского региона. На счету Т. Г. Миннияхметовой более семидесяти фольклорно-этнографических и фольклорно-диалектологических экспедиций, в которые она выезжала как самостоятельно, так и в сопровождении коллег, в том 
числе в составе экспедиций, организованных зарубежными учеными. Ею собран мощный банк во многом уже исчезнувшей в наши дни информации по этнографии, культуре и быту удмуртов и других народов региона; имеется большой фонд фото-, видео- и аудиоматериалов.

Прекрасное знание зарубежной научной литературы и современных тенденций развития европейской этнологии и мифологии позволяет Т. Г. Миннияхметовой рассматривать удмуртские материалы на широком историко-культурном фоне, анализировать новые аспекты и грани развития национальной удмуртской культуры. Важно отметить, что эта осведомлённость и принадлежность к удмуртской нации позволяют ей изучать избранную тему как исследователю, знающему этническую культуру «изнутри», а также в контексте развития современных этнических процессов. Научная и преподавательская деятельность Татьяны Гильнияхметовны способствует широкой популяризации удмуртской этнографии и фольклора в европейской и мировой научной среде. Благодаря её публикациям и выступлениям на международных научных форумах, большой лекционной работе язык, культура, быт и верования удмуртов становятся известными широкой научной общественности во многих странах Европы и Азии. Она является членом редколлегии журналов "Mäetagused" (Эстония), "Yearbook of Balkan and Baltic Studies (Ежегодник балканских и балтийских исследований)" (Болгария, Литва, Эстония), «Ежегодник финно-угорских исследований = Yearbook of Finno-Ugric Studies» (Россия), «Вестник угроведения» и ежегодного периодического сборника “The Ritual Year".

Т. Г. Миннияхметова - автор семи авторских и коллективных монографий, около двухсот научных статей. Она владеет многими европейскими языками; пишет и публикует свои труды на русском, удмуртском, венгерском, финском, эстонском, английском, немецком, корейском языках.

Черты личности. Татьяна Гильнияхметовна Миннияхметова - одна из наших ярких удмуртских «звезд» (яркыт удмурт кизили), достойная дочь своего народа. Ее энергия, неординарность, жизнелюбие, неотразимый юмор привлекают людей. Она всегда готова прийти на помощь товарищам, сделать доброе дело для родных, друзей, коллег и знакомых. Ради этого иногда взваливает на себя многочисленные обязанности и обязательства. Она любящая дочь, сестра, тётя, надежный друг. Эта элегантная, современная, динамичная женщина предана своему делу, но не теряет интереса и ко всему происходящему вокруг. И хотя Татьяна Гильнияхметовна на протяжении нескольких десятков лет проживает за рубежом, она сохраняет в себе ту прочную нравственную основу, которая позволяет ей оставаться причастной к своей нации, быть гражданином и патриотом своей «малой родины» и России.

Поступила в редакцию 15.01.2021

Шутова Надежда Ивановна, доктор исторических наук, ведущий научный сотрудник, Удмуртский институт истории, языка и литературы УдмФИЦ УрО РАН 426004, Россия, г. Ижевск, ул. Ломоносова, 4 e-mail:nad_shutova@mail.ru

\section{N. I. Shutova \\ LIFE DEDICATED TO STUDY THE TRADITIONAL UDMURT CULTURE: ON THE SIXTIETH ANNIVERSARY OF THE ETHNOLOGIST TATIANA GILNIYAKHMETOVNA MINNIYAKHMETOVA}

DOI: $10.35634 / 2224-9443-2021-15-1-188-192$

The article is devoted to the anniversary of Tatyana Gilnyakhmetovna Minniyakhmetova, the prominent ethnologist and Candidate of Historical Sciences, Doctor of Philosophy, Excellence in Public Education of the RSFSR (Moscow, 1987). The author focuses on her formation stages as a researcher, her scientific, popularizing and organizational activities and her contribution to the study of Udmurt traditional culture. During the period 
of the scientific research T. Minniyakhmetova published eight single author and multi-author monographs and more than two hundred articles in Udmurt traditional culture. Her research works are in demand by the professional academic community and universities, and researchers of the Higher School, and by everyone who is interested in the culture and history of the Udmurt people. She has organized and conducted more than seventy folkloristic-ethnographic and folkloristic-dialectological expeditions, the geography of which in addition to the Trans-Kama region and Udmurt Republic which covers the neighbouring territories of the Volga and Ural area, as well as some regions of Siberia. T. Minniyakhmetova has collected the solid bank of information on ethnography, culture and life of the Udmurts as well as other ethnic groups of the Volga-Ural region. There is the large fund of photographic materials, video and audio recordings in her collection. The name of the Udmurt ethnologist is known not only in Russia, but also outside of the country. The Udmurt origin and her experiences of tendencies of European ethnology allow T. Minniyakhmetova to act both as a researcher who knows ethnic culture from the inside and in the context of the development of modern ethnic processes. Through her scientific and teaching activities, she contributes to the wide popularization of Udmurt ethnography and folklore in the European and global scientific community.

According to the traditional concepts of the Udmurts, Tatiana Minniyakhmetova developed anthropological theories on ethnic self-consciousness, concepts of ritual and doubled ritual time, peculiarities of the orientation in space (spacial intimacy and spacial contradiction), real and symbolic boundaries, the concept of clean/pure and unclean/impure, the birth of life and the creation of souls, interactive methods of communication between the living and the dead, methodology of field researches.

Keywords: Tatiana Minniyakhmetova, Trans-Kama Udmurts, Traditional Culture, Ethnic Identity, Folklore, Anniversary.

Citation: Yearbook of Finno-Ugric Studies, 2021, vol. 15, issue 1, pp. 188-192. In Russian.

Received 15.01.2021

Shutova Nadezhda Ivanovna,

Doctor of Historical Sciences, Leading Research Associate Udmurt Institute of History, Language and Literature, Udmurt Federal Research Center of the Ural Branch, Russian Academy of Sciences

Lomonosovast., 4, Izhevsk, 426004, Russian Federation e-mail: nad_shutova@mail.ru 